\title{
Perspective of Monitoring Heavy Metals by Moss Visible Chlorophyll Fluorescence Parameters
}

\section{OPEN ACCESS}

Edited by:

Vasilij Goltsev,

Sofia University, Bulgaria

Reviewed by:

Carmen Arena

University of Naples Federico II, Italy

Misao Itouga,

RIKEN Center for Sustainable

Resource Science (CSRS), Japan

*Correspondence:

Shu Yuan

roundtree318@hotmail.com

${ }^{t}$ These authors have contributed equally to this work

Specialty section:

This article was submitted to Plant Abiotic Stress,

a section of the journal

Frontiers in Plant Science

Received: 27 September 2018

Accepted: 10 January 2019

Published: 25 January 2019

Citation:

Chen Y-E, Wu N, Zhang Z-W

Yuan M and Yuan S (2019)

Perspective of Monitoring Heavy Metals by Moss Visible Chlorophyll

Fluorescence Parameters.

Front. Plant Sci. 10:35

doi: $10.3389 /$ fpls.2019.00035

\author{
Yang-Er Chen ${ }^{1 \dagger}$, Nan Wu ${ }^{1 \dagger}$, Zhong-Wei Zhang ${ }^{2}$, Ming Yuan ${ }^{1}$ and Shu Yuan ${ }^{2 *}$ \\ 'College of Life Science, Sichuan Agricultural University, Ya'an, China, ${ }^{2}$ College of Resources, Sichuan Agricultural \\ University, Chengdu, China
}

Chlorophyll fluorescence measurements have been mainly applied to investigate the functioning of the photosynthetic apparatus in the diagnosis of environmental stress. Moss is sensitive to several abiotic stresses and is considered an environmental indicator. Therefore, moss chlorophyll fluorescence can be as a visual parameter applicable for monitoring heavy metal contaminants in water. Different from previous studies with value changes of chlorophyll fluorescence in mosses, we suggest that phenotypes with anthocyanin accumulation pattern and chlorosis pattern and colors of chlorophyll fluorescence images of the maximum efficiency of PSIl photochemistry (Fv/Fm) and the quantum yield of PSII electron transport ( $\left.\Phi_{P S I I}\right)$ could reflect metal species groups and concentrations roughly. And we further indicated that $\mathrm{Cr}(\mathrm{III})$ and $\mathrm{Cr}(\mathrm{VI})$ could be monitored distinguishably according to the non-photochemical quenching (NPQ) fluorescence of sporadic purple and sporadic lavender images, respectively. It is interesting that the fluorescence color patterns were nearly the same for all treatment concentrations. This perspective provides additional data of chlorophyll fluorescence changes in moss under cold, heat, salinity, high light or osmotic stress. Only heat stress and high light have significant effects on the fluorescence parameters of FV/Fm and $\Phi_{P S I I}$. In contrast, mosses are less sensitive to short-term cold, salinity, and osmotic stress. While NPQ decreases rapidly under the osmotic stress. Nevertheless, heat stress, high light or osmotic stress does not usually co-occur in the place where the moss grows. Estimation through moss chlorophyll fluorescence color patterns is still a rapid and non-invasive method to monitor heavy metal pollutions in water.

Keywords: chlorophyll fluorescence, moss, abiotic stress, heavy metal monitoring, non-photochemical quenching

\section{INTRODUCTION}

As a result of global climate change, an increase in temperature, changes in precipitation pattern, stress by various environmental factors, alone or in combination, leads to a degradation of natural ecosystems (Hu et al., 2018). Evaluation of the physiological state of plants, their activity, monitoring the physical existence and intensity of environmental stress by operable methods can provide essential information for ecosystem management. Various experimental approaches and analytical methods have been developed for in vivo monitoring of plants' physiological state, stress response, and tolerance, including RGB (red, green, and blue) imaging (Berger et al., 2010), thermal 
imaging (Jones et al., 2009), NIR (near-infrared) imaging (Seelig et al., 2009), and chlorophyll fluorescence (Kalaji et al., 2016). Among these methods, chlorophyll fluorescence, a powerful tool extensively used to analyze the status and function of photosystem II (PSII), is now being commonly employed in detecting the damage to photosynthetic apparatus caused by environmental stress (Stirbet et al., 2018). One of the main features of chlorophyll fluorescence measuring is non-invasive diagnostics, allowing researchers to get detailed information of plant performance without destructing the tested sample (Kalaji et al., 2014).

Chlorophyll fluorescence, which contains a large amount of information on PSII photochemistry reactions provides a measure of how well plants use the light energy absorbed at PSII for electron transport and is therefore a key measure of photosynthetic activity and performance (Baker, 2008). It is well known that many abiotic stresses cause changes in the photosynthetic apparatus at different metabolic levels (Pawłowicz et al., 2012) and environmental stress factors may produce directly or indirectly deleterious effects on PSII and many plant biochemical processes (Gururani et al., 2015). However, because photosynthesis is linked to many plant metabolic pathways, the alterations of photosynthesis can represent the physiological state of the plant and therefore chlorophyll fluorescence signal can reflect the influence of environmental factors on plants to some extent (Kalaji et al., 2016). Measuring chlorophyll fluorescence provides a rapid, non-destructive, and non-invasive screening tool for plant performance and the ability to cope with stress because perturbation of chlorophyll fluorescence in metabolism is sensitive (Barbagallo et al., 2003). Moreover, chlorophyll fluorescence along with other physiological parameters can bring more complex and useful information about the mechanisms contributing to stress responses (Chen et al., 2016, 2017, 2018c). We refer the reader to numerous other in-depth reviews on principles and method of chlorophyll fluorescence (Krause and Weis, 1991; Maxwell and Johnson, 2000; Baker, 2008; Murchie and Lawson, 2013).

At present, mosses and lichens have been used widely as bioindicators of atmospheric pollution (Pott and Turpin, 1996). Some mosses have also been used to evaluate water pollution (Bruns et al., 1997). In the late 1960s, Rühling and Tyler used mosses as sensitive bioindicators for surveying heavy metal contamination (Rühling and Tyler, 1968, 1970). Since then terrestrial mosses have been widely applied for pollution biomonitoring in different countries and regions (Pott and Turpin, 1996; Ermakova et al., 2004; Shotbolt et al., 2007; Chen et al., 2010). For example, using moss bags is a common strategy to measure heavy metals directly with terrestrial mosses. This technique employs placing suitable mosses, collected from clean areas, in a mesh net bag and measuring concentrations of contaminants in samples exposed to a polluted area (Ares et al., 2012). However, many methods using mosses for biomonitoring like moss bags are time-consuming, inconvenient and do not indicate the contaminants in situ immediately.

Moss rhizoid is too short to monitor deep soil pollution and therefore it is only used to monitor heavy metals in aquatic environment accurately. Based on the previous researches using chlorophyll fluorescence to detect abiotic stresses in the aquatic bioindicator mosses (Rau et al., 2007; Proctor and Smirnoff, 2011; Liepiņa and Ievinsh, 2013; Kangas et al., 2014; Jägerbrand and Kudo, 2016), we provided new ideas to monitor water heavy metals rapidly and non-invasively in a large-scale by moss visible parameters of $\mathrm{Fv} / \mathrm{Fm}$ and $\Phi_{\mathrm{PSII}}$ (Chen et al., 2015a). In other words, metal contaminations could be roughly estimated visually using the chlorophyll fluorescence images. This perspective provides further information about chlorophyll fluorescence changes in moss under cold, heat, salt stress, high light or osmotic stress. Only heat stress and high light had significant effects on $\mathrm{Fv} / \mathrm{Fm}$ and $\Phi_{\mathrm{PSII}}$. However, mosses are less sensitive to cold, salt stress or osmotic stress. While NPQ decreased rapidly under the osmotic stress. Fortunately, heat stress, high light, and osmotic stress do not usually co-occur in heavy-metal-polluted water. Moss fluorescence imaging is still a rapid and non-invasive method to monitor heavy metal contaminations in water. Moreover, insufficiency of this method and future research directions also are discussed.

\section{MOSS AS AN INDICATOR PLANT}

Mosses are suitable objects for biomonitoring because of their extreme ability to accumulate pollutants such as heavy metals, radioisotopes and multifold chemical pollutants (Carballeira et al., 2006). The reasons for this over-accumulation capacity of mosses include the lack of the complex regulatory mechanisms of vascular plants due to the deficiency of a real root and vascular system (Tyler, 1990). In mosses, the leaves, which mostly lack a protective cuticle, normally have only a layer of cells and consequently offer a large surface for absorption (Ares et al., 2012). They readily absorb most of their nutrients and pollutants directly from atmosphere and precipitation through the entire surfaces (Tyler, 1990). As a result, Mosses can be applied to monitor heavy metals in aquatic environment, such as water, wetland, and moist soil surface. Mosses are more quickly and seriously poisoned by pollutants than vascular plants, and reflect with their specific victimization symptoms (Vanderpoorten and Goffinet, 2009).

\section{BIOMONITORING HEAVY METAL CONTAMINATIONS BY CHLOROPHYLL FLUORESCENCE PARAMETERS IN MOSSES}

Heavy metal majorly affects chloroplast ultrastructure, causing lipid peroxidation in photosynthetic membranes, degrades photosynthetic pigments, inhibits PSII activity and electron transport, decreases carboxylation efficiency of Rubisco and restrains net photosynthetic rate (Mishra and Dubey, 2005). Previous research has suggested that the ratio of $\mathrm{Fv} / \mathrm{Fm}$ of aquatic moss Fontinalis antipyretica could be used as an indicator of heavy metal toxicity (Rau et al., 2007). Other studies have only used chlorophyll fluorescence as one of the test parameters, along with other physiological parameters, to explore the effects 
of heavy metal stress on moss. Our previous experimental data (Chen et al., 2015a, 2018a) of chlorophyll fluorescence changes in mosses under heavy metal stress are summarized in Figure 1. In our previous report (Chen et al., 2015a), two moss species Taxiphyllum taxirameum and Eurhynchium eustegium were compared. They showed similar chlorophyll fluorescence images under metal stresses (the same color patterns with slightly different values). However, T. taxirameum has larger-area leaves than E. eustegium, and therefore is better for observing chlorophyll fluorescence changes. On the other hand, T. taxirameum has more branches and forms dense carpet than other hydrophilous moss species, which increases its capacity to concentrate heavy metals from the water. Therefore the heavy metal accumulation ability of $T$. taxirameum was higher than other hydrophilous moss species (Chen et al., 2010, 2015b).

Phenotypes with anthocyanin accumulation pattern and chlorosis pattern and colors and values of chlorophyll fluorescence images of $\mathrm{Fv} / \mathrm{Fm}$ and $\Phi_{\text {PSII }}$ could reflect metal species groups and concentrations roughly (Figure 1). Furthermore, the fluorescence color patterns were nearly the same for all concentrations $(10,25$, or $50 \mu \mathrm{M})$ of the same heavy metal treatments, although the high concentration $(50 \mu \mathrm{M})$ led

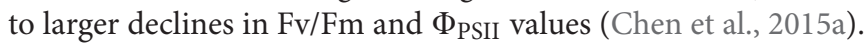
The phenotype of non-stressed mosses was bright green. Copper and Zinc $(\leq 50 \mu \mathrm{M})$ did not cause apparent chlorosis but caused noticeable anthocyanin accumulation in leaves. $\mathrm{Pb}$ and $\mathrm{Cr}$ led partial chlorosis and slightly less anthocyanin accumulation. Cd and $\mathrm{Hg}$ did not induce observable anthocyanin accumulation, but instead induced partial or complete chlorosis, respectively, in the entire moss, perhaps due to a large amount of damage to moss cells. The color of Fv/Fm and $\Phi_{\text {PSII }}$ image is uniform blue and green in a control moss, respectively. Then, the color of Fv/Fm and $\Phi_{\text {PSII }}$ image is blue with sporadic green and green with sporadic yellow for $\mathrm{Cu}$ and $\mathrm{Zn}$-treated mosses, respectively. Lead and Chromium treatment forms Fv/Fm image green with sporadic blue and $\Phi_{\text {PSII }}$ image turns green with sporadic red. The color of Fv/Fm image is green with sporadic red for Cadmiumtreated mosses and a large dark area for Mercury-treated mosses as well as $\Phi_{\text {PSII }}$ image is a large dark area on Cadmium and Mercury treatment. It is interesting to note that the basal tissues show higher Fv/Fm and $\Phi_{\text {PSII }}$ fluorescence (blue to green colors) than the apical tissues (green to yellow colors); contrastingly, the basal tissues present much lower NPQ fluorescence (red to black colors) than the apical tissues (green to yellow colors; Chen et al., 2015b, 2018a). These differences may suggest that the apical tissues are subjected to more severe damages than the basal tissues during the metal stress. Correspondingly, more superoxide accumulation and more cell death were observed for the apical tissues than the basal tissues (Chen et al., 2015b, 2018a).

The colors changes indicate great reductions in these parameters. For example, 5-20\% declines in Fv/Fm and $\Phi_{\text {PSII }}$ values indicate approximate $10 \mu \mathrm{M}$ metal ions; $20-40 \%$ declines in these two parameters indicate $25 \mu \mathrm{M}$ metal ions; $40-75 \%$ declines indicate $50 \mu \mathrm{M}$ metal ions. Detailed value changes have been shown in the report by Chen et al. (2015a). Despite the fact that some moss species (like Physcomitrella) has a much stronger
NPQ than higher plants (Alboresi et al., 2010; Chen et al., 2018b), the NPQ value increases in mosses treated with 10 or $25 \mu \mathrm{M}$ of metal ions, but decreases at $50 \mu \mathrm{M}$, and the color varies largely (therefore not shown in Figure 1). The detection limits are in great variation among different metal species groups. $50 \mu \mathrm{M} \mathrm{Cu}$, $\mathrm{Zn}, \mathrm{Pb}$, or $\mathrm{Cr}(\mathrm{VI})$ treatments would result in about half declines in Fv/Fm and $\Phi_{\text {PSII }}$ values. However, over $70 \%$ declines could be observed for $50 \mu \mathrm{M} \mathrm{Cd}$ or $\mathrm{Hg}$ ions (a large dark area on the chlorophyll fluorescence image). Therefore, $50 \mu \mathrm{M}$ is the detection limit for Cd or Hg contaminants (Chen et al., 2015a). While for less toxic metal ions, the detection limits may be up to 500 MM (Chen et al., 2015b, 2018a).

Moreover, we reported the difference of toxicity between trivalent chromium and hexavalent chromium using chlorophyll fluorescence (Chen et al., 2018a), and found that Cr (III) and $\mathrm{Cr}$ (VI) could be monitored distinguishably according to the NPQ of sporadic purple and sporadic lavender images, respectively (Figure 1). White-purple spots appear on the edges of the leaves at the apical tissues in the NPQ image for $\mathrm{Cr}$ (VI)-treated mosses. As the Cr (VI) treatment concentration increases, whitepurple points increasingly begin to appear. However, regardless of the concentration of $\mathrm{Cr}$ (III), the NPQ image of Cr (III)treated mosses is mostly blue-purple patches with no whitepurple spots (Chen et al., 2018a). White-purple spots present extremely high NPQ values on these points, also indicating that apical tissues have higher NPQ fluorescence than the basal tissues. Detailed value changes have been shown in the report by Chen et al. (2018a). Our previous report indicated that the uptake of Cr (VI) was much easier than Cr (III) in moss plants (almost two times higher). Thus for less mobile Cr (III) ions, the detection limits may be further up to $1000 \mu \mathrm{M}$ (Chen et al., 2018a).

Chlorophyll fluorescence appeared to be a useful technique to monitor heavy metals in water or on wetland and humid soil surface without destructive measurements. However, two or more metal contaminants may co-exist in a natural environment. For example, it is also difficult to judge the degree of $\mathrm{Cr}$ pollution if other heavy metal contaminants are present. Therefore, this method is suitable for detecting single $\mathrm{Cr}$ contaminations in an area known to be polluted by $\mathrm{Cr}$ (Chen et al., 2018a).

\section{OTHER ABIOTIC STRESSES MAY NOT AFFECT HEAVY METAL BIOMONITORING BY MOSS CHLOROPHYLL FLUORESCENCE}

Despite the well-documented influence of abiotic stress on photosynthetic processes and chlorophyll fluorescence being explored in many higher plants (Kalaji et al., 2016), the relationship between abiotic stress and chlorophyll fluorescence of mosses is weakly summarized in the literature. An experiment was carried out to observe how the chlorophyll fluorescence of moss changed under several common stresses, including cold, heat, salinity, high light, and osmotic stress. The experimental results have been shown in Figure 2. 


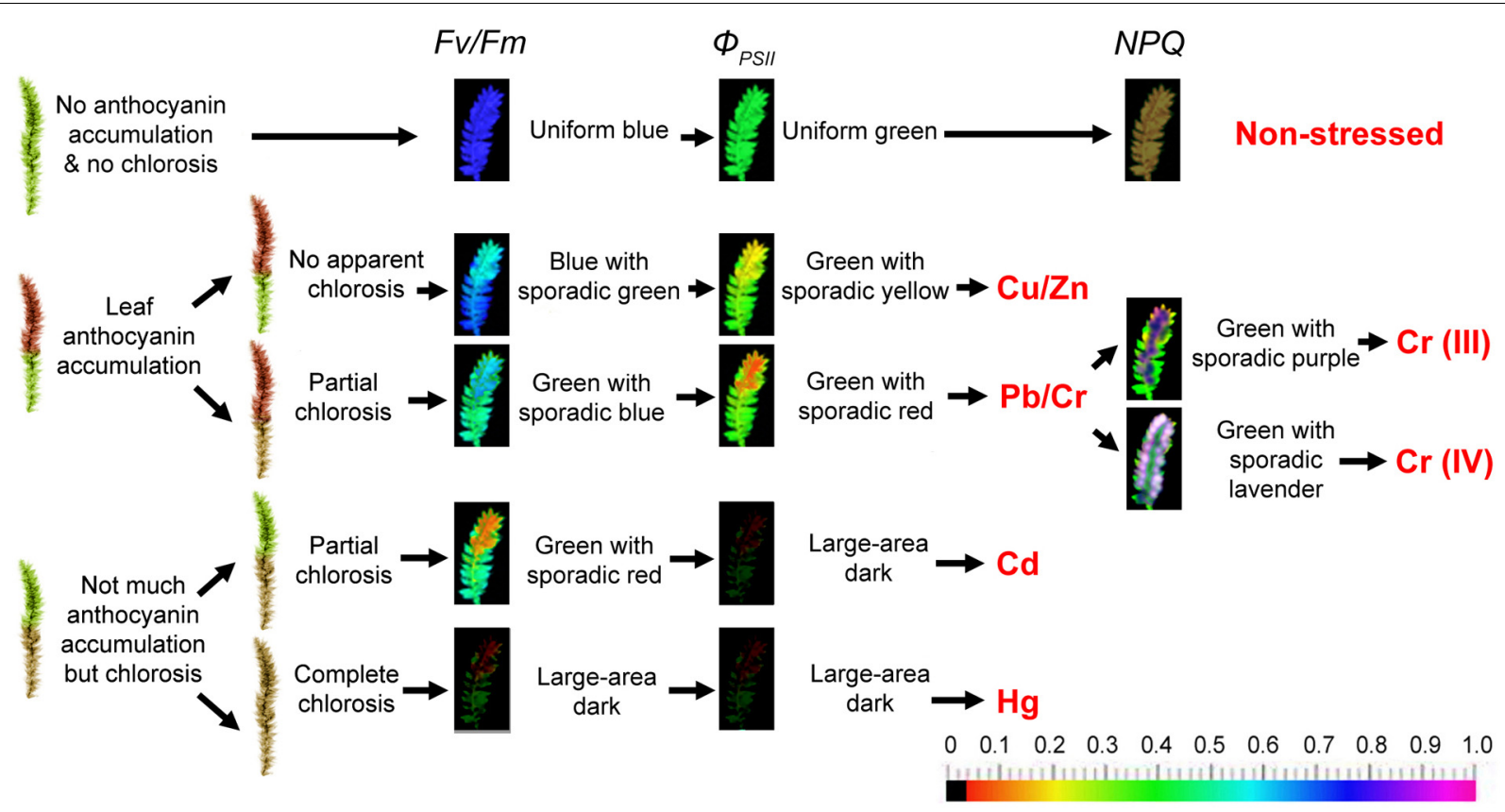

FIGURE 1 | Putative heavy metal estimation criteria of moss phenotype and chlorophyll fluorescence imaging. The moss was cultured in distilled sterile modified Mohr medium $\left(\mathrm{KNO}_{3} 100 \mathrm{mg}, \mathrm{CaCl}_{2} \cdot 4 \mathrm{H}_{2} \mathrm{O} 10 \mathrm{mg}, \mathrm{MgSO}_{4} 10 \mathrm{mg}, \mathrm{KH}_{2} \mathrm{PO}_{4} 136 \mathrm{mg}\right.$, and FeSO $40.4 \mathrm{mg}$ to $1000 \mathrm{~mL}$ distilled water, pH 7.5$)$ for 3 days in lab before the metal stress to make them adjust to indoor environment (16/8 h photoperiod at $100 \mu \mathrm{mol}$ of photons $\left.\mathrm{m}^{-2} \mathrm{~s}^{-1}, 25 \pm 1{ }^{\circ} \mathrm{C}\right)$. Metal stresses applied by adding 0 (control), 10,25 , or $50 \mu \mathrm{M} \mathrm{CuSO}_{4} .5 \mathrm{H}_{2} \mathrm{O}, \mathrm{ZnSO}_{4} .7 \mathrm{H}_{2} \mathrm{O}, \mathrm{Pb}\left(\mathrm{NO}_{3}\right)_{2}, \mathrm{CrCl}_{3}, \mathrm{~K}_{2} \mathrm{CrO}_{4}, \mathrm{CdCl}_{2} .2 .5 \mathrm{H}_{2} \mathrm{O}, \mathrm{HgCl}_{2}$ to the Mohr solution. Solutions were replaced every 2 days. The mosses were cultured or stressed for 30 days. Chlorophyll fluorescence images were obtained at room temperature using a modulated imaging fluorometer (the Imaging PAM M-Series Chlorophyll Fluorescence System, Heinz-Walz Instruments, Effeltrich, Germany) according to the instructions provided by the manufacturer. Images of Fv/Fm after dark adaptation and of $\Phi_{\mathrm{PS} \|}$ and NPQ at the steady-state of the induction curve with actinic illumination of $100 \mu \mathrm{mol}$ photons $\mathrm{m}^{-2} \mathrm{~s}^{-1}$. The color scale shows at the bottom of the figure represents the range from 0 (black) to 1.0 (purple) for each parameter. Diagrams representing T. taxirameum chlorophyll fluorescence are shown. NPQ increases in mosses treated with 10 or $25 \mu \mathrm{M}$ of metal ions, but decreases at $50 \mu \mathrm{M}$, and the color varies largely, therefore not shown in the figure.

Only heat stress and high light have a significant effect on the fluorescence parameters of $T$. taxirameum among five stresses. In contrast, $T$. taxirameum is less sensitive to shortterm cold, salinity, and osmotic stress as the fluorescence parameters do not change much with the timed exposure. When chlorophyll fluorescence of moss is used to biomonitor heavy metal contamination in aquatic environment, where both heat stress and high light are present at the same time, the fluorescence parameters are seriously reduced, resulting in an inaccurate observation. However, the effects of cold, salinity, and osmotic stress are minimal. It is important to note that the value of NPQ decreases rapidly under osmotic stress, so it should not be possible to distinguish $\mathrm{Cr}$ (VI) from Cr (III) by a NPQ image when there is osmotic stress. The fluorescence parameters of mosses are diverse under five stresses, so the detailed mechanism remains to be further studied.

Mosses are usually grown in the shaded (cool) and humid (water) environments, such as the shallow water or the soil at the water's edge, where heat stress, high light or osmotic stress does not usually co-occur. Alternatively, we should not select mosses grown under high-light conditions when acquiring chlorophyll fluorescence images. Although mosses may encounter low temperature or salinity, these two environmental stresses do not affect the chlorophyll fluorescence significantly. Thus, heat stress, high light, or osmotic stress may not compromise the accuracy of heavy metal biomonitoring through the moss chlorophyll fluorescence.

\section{CONCLUSION AND PERSPECTIVES}

Chlorophyll fluorescence tool provides useful information about plant photosynthetic performance and the extent to which this performance is limited by photochemical and non-photochemical processes. As reported in this article, this technique has been conveniently used in stress researches where it provides the possibility to detect the responses of mosses to abiotic stresses. Previous studies provide new ideas to monitor water heavy metal rapidly and non-invasively in a large-scale using moss chlorophyll fluorescence parameters with imaging. However, it is difficult to identify specific stresses in any plant including moss directly through chlorophyll fluorescence tool for the time being. In the laboratory, it is easy to create a single controllable stress condition to induce clear symptoms, whereas in the field, plant is often exposed to several joint stresses at the same time. Nevertheless, mosses are usually grown in the shaded and humid environments without heat stress, high 
A

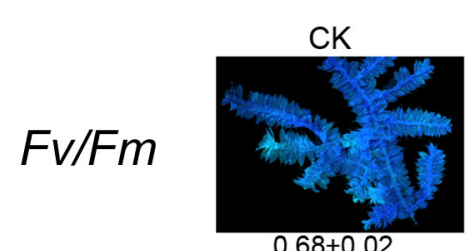

Salinity

$0.68 \pm 0.02$

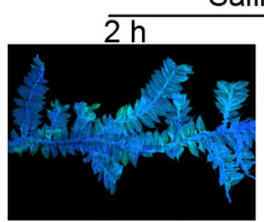

$0.65 \pm 0.03$

B

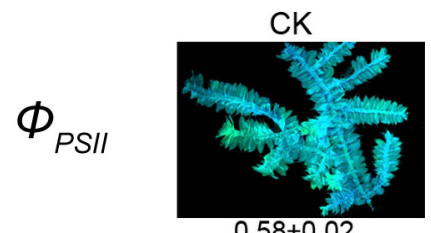

Salinity

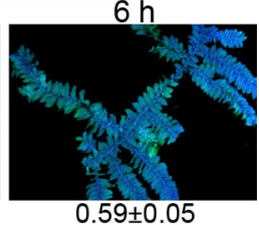

$0.59 \pm 0.05$

$0.58 \pm 0.02$

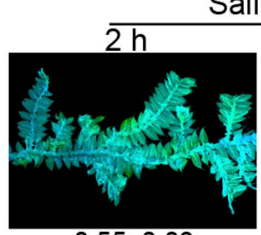

$0.55 \pm 0.03$

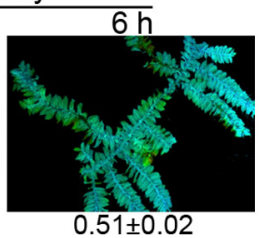

$0.51 \pm 0.02$

C

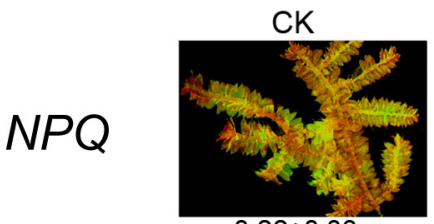

Salinity

$0.22 \pm 0.03$

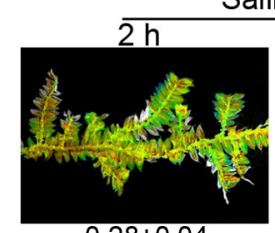

$0.28 \pm 0.04$

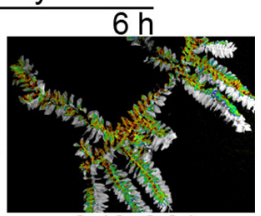

$0.49 \pm 0.04$

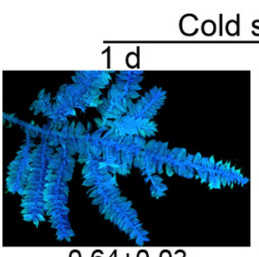

$0.64 \pm 0.03$

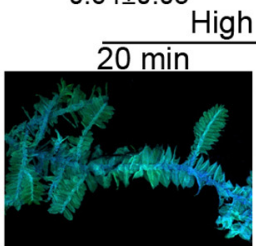

$0.58 \pm 0.04$

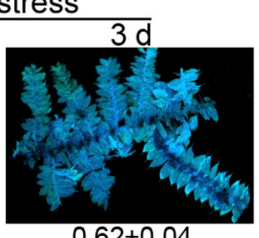

$0.62 \pm 0.04$

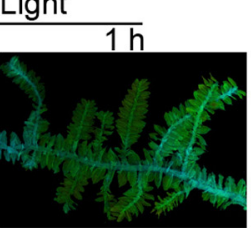

$0.43 \pm 0.03$
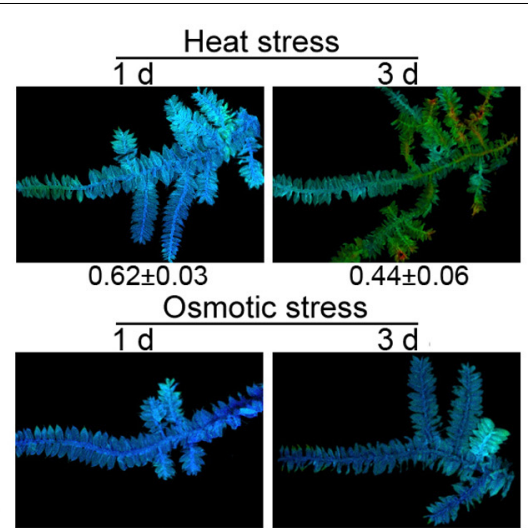

$0.65 \pm 0.03$

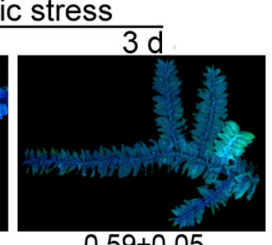

$0.59 \pm 0.05$

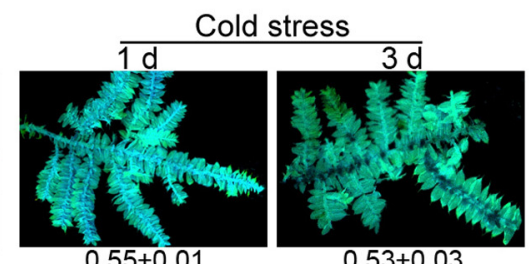

$0.55 \pm 0.01$

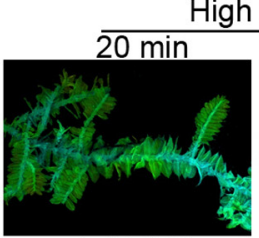

$0.47 \pm 0.03$

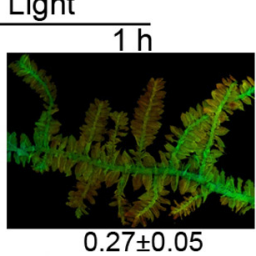

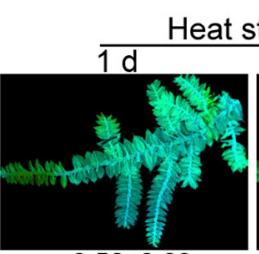

$0.52 \pm 0.03$

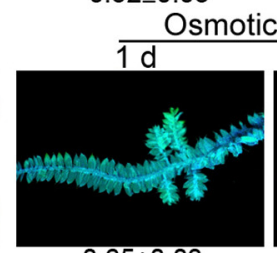

$0.65 \pm 0.03$

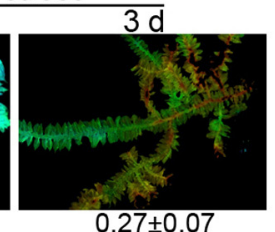

$0.27 \pm 0.07$

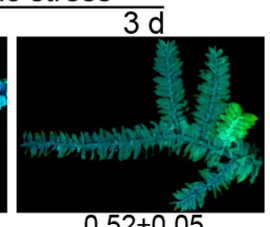

$0.52 \pm 0.05$

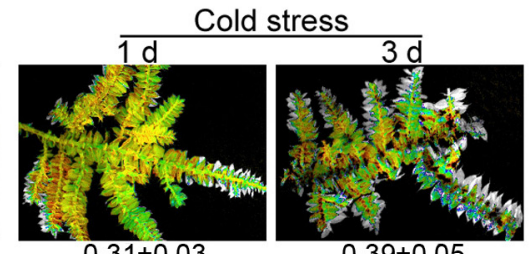

High Light

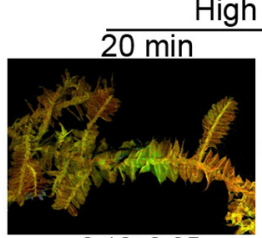

$0.18 \pm 0.05$

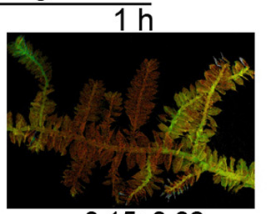

$0.15 \pm 0.02$

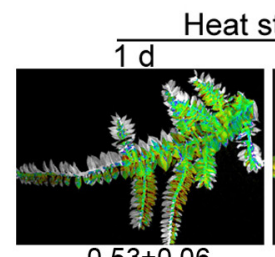

$0.53 \pm 0.06$

Osmotic stress

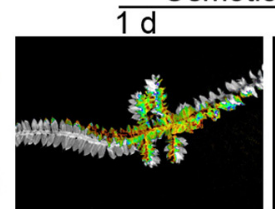

$0.17 \pm 0.11$

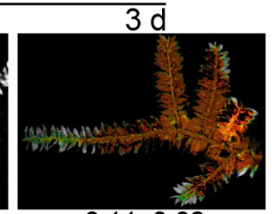

$0.11 \pm 0.02$

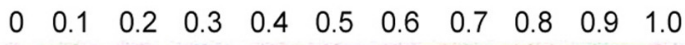

FIGURE 2 | Chlorophyll fluorescence imaging of $T$. taxirameum under cold stress, heat stress, salt stress, high light, and osmotic stress. Experimental materials were T. taxirameum (Mitt.) Fleisch, which were collected in Sichuan Agricultural University (Ya'an, China) and brought back to laboratory to be thoroughly washed. T. taxirameum were further acclimatized in distilled sterile modified Mohr medium for 3 days under the controlled conditions $(16 / 8 \mathrm{~h} \mathrm{light/dark} \mathrm{cycles} \mathrm{at} 100 \mu \mathrm{mol}$ of photons $\mathrm{m}^{-2} \mathrm{~s}^{-1}, 25 \pm 1^{\circ} \mathrm{C}$ ) before stress treatment. Adapted mosses were transferred to $10^{\circ} \mathrm{C}$ or $45^{\circ} \mathrm{C} 1$ day/3 days for cold or heat stress. For salt stress, adapted mosses were placed in $300 \mathrm{mM} \mathrm{NaCl}$ solution for 2 or $6 \mathrm{~h}$. For high-light stress, adapted mosses were placed at $1000 \mu \mathrm{mol}$ of light photons $\mathrm{m}^{-2} \mathrm{~s}^{-1}$, $25 \pm 1^{\circ} \mathrm{C}$ for $20 \mathrm{~min}$ or $1 \mathrm{~h}$. Adapted mosses were placed in $20 \%$ PEG solution for 1 or 3 days for osmotic stress. Chlorophyll fluorescence images were obtained at room temperature using a modulated imaging fluorometer (the Imaging PAM M-Series Chlorophyll Fluorescence System, Heinz-Walz Instruments, Effeltrich, Germany) according to the instructions provided by the manufacturer. Images of Fv/Fm after dark adaptation and of $\Phi_{P S I I}$ and NPQ at the steady-state of the induction curve with actinic illumination of $100 \mu \mathrm{mol}$ photons $\mathrm{m}^{-2} \mathrm{~s}^{-1}$. The color scale shows at the bottom of the figure represents the range from 0 (black) to 1.0 (purple) for each parameter. (A-C) Means the three chlorophyll fluorescence parameters Fv/Fm, $\Phi_{P S I I}$, and NPQ respectively. 
light or osmotic stress (or these environmental stresses can be avoided). And they are insensitive to low temperature or salinity. Thus, other environmental factors may not affect heavy metal biomonitoring by the moss-chlorophyll-fluorescence method.

For highly toxic metal ions (such as $\mathrm{Cd}$ and $\mathrm{Hg}$ ), the detection limit is about $50 \mu \mathrm{M}$, contrasting to $500 \mu \mathrm{M}$ for low toxic metal ions. However, $\mathrm{Cd}$ or $\mathrm{Hg}$ ion concentrations may exceed $50 \mu \mathrm{M}$ in some heavily polluted water. How to monitor these metal ions at extremely high levels needs further investigation. Our previous work only considered the case of a certain heavy metal stress, but mosses often suffer many heavy metals at the same time in the real natural environment. Studying the chlorophyll fluorescence of the moss after multiple heavy metals treatments will be the future research direction. In addition, the effect of water organic matter pollution on the chlorophyll fluorescence of moss has not been studied, and it is therefore another research direction for the future. Nevertheless, a single mine water pollution usually contains only one major metal iron. For example, lead mine often contaminates nearby surface water by letting out $\mathrm{Pb}$ irons. While chromium occurs naturally as both a chromite $\left(\mathrm{FeCr}_{2} \mathrm{O}_{4}\right)$ in serpentine and ultramafic rocks and mostly exists in trivalent $\mathrm{Cr}$ (Becquer et al., 2003). Our method with the moss chlorophyll fluorescence may be especially useful to monitor heavy metal in the surface water of mining areas. However, for monitoring industrial contaminants (mixtures of toxic organic pollutants and inorganic pollutants including heavy metals), more feasible methods still need to be developed.

Most previous studies of moss chlorophyll fluorescence (Rau et al., 2007; Proctor and Smirnoff, 2011; Liepiņa and Ievinsh, 2013; Kangas et al., 2014; Jägerbrand and Kudo, 2016) focused on the fluorescence value changes. Our former studies (Chen et al., 2015a, 2018a) and the data proposed in this perspective suggest that color patterns of the fluorescence images could reflect metal

\section{REFERENCES}

Alboresi, A., Gerotto, C., Giacometti, G. M., Bassi, R., and Morosinotto, T. (2010). Physcomitrella patens mutants affected on heat dissipation clarify the evolution of photoprotection mechanisms upon land colonization. Proc. Natl. Acad. Sci. U.S.A. 107, 11128-11133. doi: 10.1073/pnas. 1002873107

Ares, A., Aboal, J. R., Carballeira, A., Giordano, S., Adamo, P., and Fernández, J. A. (2012). Moss bag biomonitoring: a methodological review. Sci. Total Environ. 432, 143-158. doi: 10.1016/j.scitotenv.2012.05.087

Baker, N. R. (2008). Chlorophyll fluorescence: a probe of photosynthesis in vivo. Annu. Rev. Plant Biol. 59, 89-113. doi: 10.1146/annurev.arplant.59.032607. 092759

Barbagallo, R. P., Oxborough, K., Pallett, K. E., and Baker, N. R. (2003). Rapid, noninvasive screening for perturbations of metabolism and plant growth using chlorophyll fluorescence imaging. Plant Physiol. 132, 485-493. doi: 10.1104/pp. 102.018093

Becquer, T., Quantin, C., Sicot, M., and Boudot, J. P. (2003). Chromium availability in ultramafic soils from New Caledonia. Sci. Total Environ. 301, 251-261. doi: 10.1016/S0048-9697(02)00298-X

Berger, B., Parent, B., and Tester, M. (2010). High-throughput shoot imaging to study drought responses. J. Exp. Bot. 61, 3519-3528. doi: 10.1093/jxb/erq201

Bruns, I., Friese, K., Markert, B., and Krauss, G.-J. (1997). The use of Fontinalis antipyretica L. ex Hedw. as a bioindicator for heavy metals. 2. Heavy metal accumulation and physiological reaction of Fontinalis antipyretica L. ex Hedw. species groups and concentrations. And the color pattern remains stable as the metal concentration increases. For Fv/Fm and $\Phi_{\text {PSII }}$, a higher treatment concentration would result in a larger area of colors representing low fluorescence values. For example of $\mathrm{Cd}$ treatments, $50 \mu \mathrm{M}$ led to a larger area of red on Fv/Fm image, than that of $10 \mu \mathrm{M}$ treatment. However, the color pattern always is "Green with sporadic red," regardless of the concentration of Cd (Chen et al., 2015a). Metal-iron-specific fluorescence color pattern can only be observed in moss plants, but not in higher plants (data not shown). Different colors on the same moss thallus may indicate different accumulations of metal irons at different parts of the thallus, or possible translocation of metal irons within a thallus, or some particularity of moss chlorophyll fluorescence, which requires further explorations.

\section{AUTHOR CONTRIBUTIONS}

Y-EC and SY conceived the perspective and wrote the manuscript. NW collected the data. Z-WZ and MY helped to writing the manuscript.

\section{FUNDING}

This research was supported by the National Natural Science Foundation of China (31770322).

\section{ACKNOWLEDGMENTS}

We thank Dr. Shozeb Haider (University College London) for critical reading and language polishing during the preparation of this manuscript.

in active biomonitoring in the River Elbe. Sci. Total Environ. 204, 161-176. doi: 10.1016/S0048-9697(97)00174-5

Carballeira, A., Fernández, J. Á., Aboal, J. R., Real, C., and Couto, J. A. (2006). Moss: a powerful tool for dioxin monitoring. Atmos. Environ. 40, 5776-5786. doi: 10.1016/j.atmosenv.2006.05.016

Chen, Y. E., Cui, J. M., Yang, J. C., Zhang, Z. W., Yuan, M., Song, C., et al. (2015a). Biomonitoring heavy metal contaminations by moss visible parameters. J. Hazard. Mater. 296, 201-209. doi: 10.1016/j.jhazmat.2015.04.060

Chen, Y. E., Yuan, M., Zhang, H. Y., Zeng, X. Y., Liu, H. M., and Du, X. G. (2015b). Influences of $\mathrm{Cu}$ and $\mathrm{Cr}$ stress on antioxidant system and chlorophyll fluorescence in terrestrial moss Taxiphyllum taxirameum. Fresenius Environ. Bull. 24, 2211-2219.

Chen, Y. E., Liu, W. J., Su, Y. Q., Cui, J. M., Zhang, Z. W., Yuan, M., et al. (2016). Different response of photosystem II to short and long term drought stress in Arabidopsis thaliana. Physiol. Plant. 158, 225-235. doi: 10.1111/ppl.12438

Chen, Y. E., Mao, H. T., Ma, J., Wu, N., Zhang, C. M., Su, Y. Q., et al. (2018a). Biomonitoring chromium III or VI soluble pollution by moss chlorophyll fluorescence. Chemosphere 194, 220-228. doi: 10.1016/j.chemosphere.2017. 11.177

Chen, Y. E., Su, Y. Q., Mao, H. T., Wu, N., Zhu, F., Yuan, M., et al. (2018b). Terrestrial plants evolve highly-assembled photosystem complexes in adaptation to light shifts. Front. Plant Sci. 9:1811. doi: 10.3389/fpls.2018.01811

Chen, Y. E., Yuan, S., Su, Y. Q., and Wang, L. (2010). Comparison of heavy metal accumulation capacity of some indigenous mosses in Southwest China cities: a 
case study in Chengdu city. Plant Soil Environ. 56, 60-66. doi: 10.17221/160/ 2009-pse

Chen, Y. E., Zhang, C. M., Su, Y. Q., Ma, J., Mao, H. T., Yang, Z. H., et al. (2018c). Comparison of photosynthetic characteristics and antioxidant systems in different wheat strains. J. Plant Growth Regul. 37, 347-359. doi: 10.1007/ s00344-017-9731-5

Chen, Y. E., Zhang, C. M., Su, Y. Q., Ma, J., Zhang, Z. W., Yuan, M., et al. (2017). Responses of photosystem II and antioxidative systems to high light and high temperature co-stress in wheat. Environ. Exp. Bot. 135, 45-55. doi: 10.1016/j.envexpbot.2016.12.001

Ermakova, E. V., Frontasyeva, M. V., Pavlov, S. S., Povtoreiko, E. A., Steinnes, E., and Cheremisina, Y. N. (2004). Air pollution studies in Central Russia (Tver and Yaroslavl regions) using the moss biomonitoring technique and neutron activation analysis. J. Atmos. Chem. 49, 549-561. doi: 10.1007/s10874-0041265-0

Gururani, M. A., Venkatesh, J., and Tran, L. S. P. (2015). Regulation of photosynthesis during abiotic stress-induced photoinhibition. Mol. Plant 8, 1304-1320. doi: 10.1016/j.molp.2015.05.005

Hu, Y. F., Shu, X. Y., He, J., Zhang, Y. L., Xiao, H. H., Tang, X. Y., et al. (2018). Storage of C, N, and P affected by afforestation with Salix cupularis in an alpine semiarid desert ecosystem. Land Degrad. Dev. 29, 188-198. doi: 10.1002/ldr. 2862

Jägerbrand, A. K., and Kudo, G. (2016). Short-term responses in maximum quantum yield of PSII (Fv/Fm) to ex situ temperature treatment of populations of bryophytes originating from different sites in Hokkaido, northern Japan. Plants 5:E22. doi: 10.3390/plants5020022

Jones, H. G., Serraj, R., Loveys, B. R., Xiong, L. Z., Wheaton, A., and Price, A. H. (2009). Thermal infrared imaging of crop canopies for the remote diagnosis and quantification of plant responses to water stress in the field. Funct. Plant Biol. 36, 978-989. doi: 10.1071/FP09123

Kalaji, H. M., Jajoo, A., Oukarroum, A., Brestic, M., Zivcak, M., Samborska, I. A., et al. (2016). Chlorophyll $a$ fluorescence as a tool to monitor physiological status of plants under abiotic stress conditions. Acta Physiol. Plant. 38:102. doi: 10.1007/s11738-016-2113-y

Kalaji, H. M., Schansker, G., Ladle, R. J., Goltsev, V., Bosa, K., Allakhverdiev, S. I., et al. (2014). Frequently asked questions about in vivo chlorophyll fluorescence: practical issues. Photosynth. Res. 122, 121-158. doi: 10.1007/s11120-014-0024-6

Kangas, L., Maanavilja, L., Hájek, T., Juurola, E., Chimner, R. A., Mehtätalo, L., et al. (2014). Photosynthetic traits of Sphagnum and feather moss species in undrained, drained and rewetted boreal spruce swamp forests. Ecol. Evol. 4, 381-396. doi: 10.1002/ece3.939

Krause, G. H., and Weis, E. (1991). Chlorophyll fluorescence and photosynthesis: the basics. Annu. Rev. Plant Physiol. Plant Mol. Biol. 42, 313-349. doi: 10.1146/ annurev.pp.42.060191.001525

Liepina, L., and Ievinsh, G. (2013). Potential for fast chlorophyll $a$ fluorescence measurement in bryophyte ecophysiology. Estonian J. Ecol. 62, 137-149. doi: 10.3176/eco.2013.2.05

Maxwell, K., and Johnson, G. N. (2000). Chlorophyll fluorescence: a practical guide. J. Exp. Bot. 51, 659-668. doi: 10.1093/jexbot/51.345.659

Mishra, S., and Dubey, R. (2005). "Heavy metal toxicity induced alterations in photosynthetic metabolism in plants," in Handbook of Photosynthesis, ed. M. Pessarakli (Boca Raton, FL: CRC Press), 827-844.
Murchie, E. H., and Lawson, T. (2013). Chlorophyll fluorescence analysis: a guide to good practice and understanding some new applications. J. Exp. Bot. 64, 3983-3998. doi: 10.1093/jxb/ert208

Pawłowicz, I., Kosmala, A., and Rapacz, M. (2012). Expression pattern of the psbO gene and its involvement in acclimation of the photosynthetic apparatus during abiotic stresses in Festuca arundinacea and F. pratensis. Acta Physiol. Plant. 34, 1915-1924. doi: 10.1007/s11738-012-0992-0

Pott, U., and Turpin, D. H. (1996). Changes in atmospheric trace element deposition in the Fraser Valley, B.C., Canada from 1960 to 1993 measured by moss monitoring with Isothecium stoloniferum. Can. J. Bot. 74, 1345-1353. doi: 10.1139/b96-163

Proctor, M. C., and Smirnoff, N. (2011). Ecophysiology of photosynthesis in bryophytes: major roles for oxygen photoreduction and non-photochemical quenching? Physiol. Plant. 141, 130-140. doi: 10.1111/j.1399-3054.2010. 01424.x

Rau, S., Miersch, J., Neumann, D., Weber, E., and Krauss, G.-J. (2007). Biochemical responses of the aquatic moss Fontinalis antipyretica to $\mathrm{CD}, \mathrm{CU}, \mathrm{Pb}$ and $\mathrm{Zn}$ determined by chlorophyll fluorescence and protein levels. Environ. Exp. Bot. 59, 299-306. doi: 10.1016/j.envexpbot.2006.03.001

Rühling, Å., and Tyler, G. (1968). An ecological approach to the lead problem. Bot. Not. 121, 321-341.

Rühling, Å., and Tyler, G. (1970). Sorption and retention of heavy metals in the woodland moss Hylocomium splendens (Hedw.) Br. et Sch. Oikos 21, 92-97.

Seelig, H.-D., Hoehn, A., Stodieck, L. S., Klaus, D. M., Adams, W. W. III, and Emery, W. J. (2009). Plant water parameters and the remote sensing $R 1300 / R 1450$ leaf water index: controlled condition dynamics during the development of water deficit stress. Irrigation Sci. 27, 357-365. doi: 10.1007/ s00271-009-0152-5

Shotbolt, L., Büker, P., and Ashmore, M. R. (2007). Reconstructing temporal trends in heavymetal deposition: assessing the value of herbarium moss samples. Environ. Pollut. 147, 120-130. doi: 10.1016/j.envpol.2006. 08.031

Stirbet, A., Lazár, D., Kromdijk, J., and Govindjee, G. (2018). Chlorophyll $a$ fluorescence induction: can just a one-second measurement be used to quantify abiotic stress responses? Photosynthetica 56, 86-104. doi: 10.1007/s11099-0180770-3

Tyler, G. (1990). Bryophytes and heavy-metals: a literature review. Bot. J. Linn. Soc. 104, 231-253. doi: 10.1111/j.1095-8339.1990.tb02220.x

Vanderpoorten, A., and Goffinet, B. (2009). Introduction to Bryophytes. New York, NY: Cambridge University Press.

Conflict of Interest Statement: The authors declare that the research was conducted in the absence of any commercial or financial relationships that could be construed as a potential conflict of interest.

Copyright (c) 2019 Chen, Wu, Zhang, Yuan and Yuan. This is an open-access article distributed under the terms of the Creative Commons Attribution License (CC BY). The use, distribution or reproduction in other forums is permitted, provided the original author(s) and the copyright owner(s) are credited and that the original publication in this journal is cited, in accordance with accepted academic practice. No use, distribution or reproduction is permitted which does not comply with these terms. 